Original Research Paper

\title{
Hybrid Ceramo-Polymeric Nano-Diamond Composites
}

\author{
${ }^{1}$ Antonio Apicella, ${ }^{1}$ Raffaella Aversa and ${ }^{2}$ Florian Ion Tiberiu Petrescu \\ ${ }^{1}$ Advanced Material Lab, Department of Architecture and Industrial Design, \\ Second University of Naples, 81031 Aversa (CE), Italy \\ ${ }^{2}$ ARoTMM-IFToMM, Bucharest Polytechnic University, Bucharest, (CE), Romania
}

Article history

Received: 27-04-2018

Revised: $11-05-2018$

Accepted: 19-05-2018

Corresponding Author: Florian Ion Tiberiu Petrescu ARoTMM-IFToMM, Bucharest Polytechnic University, Bucharest, (CE), Romania Email: scipub02@gmail.com

\begin{abstract}
This paper discusses a new class of bio-mechanical scaffolds active for tissue engineering based on a nano-diamond-filled hydrophilic polymer matrix. The new biomaterials used have special mechanical and biological properties for which they should be extensively studied for their use for various advanced biomedical applications. The new hybrid material has been prepared using 2 and $5 \%$ by volume of detonating nanodiamonds and poly (hydroxy-ethyl-methacrylate) hydrophilic. Both the mechanical and biological properties specific to the nanocomposite are hybrids in nature. The paper presents the analytical procedures of the hybrid material and the preliminary mechanical characterization. This class of hybrid materials has a high potential for biomimetic, osteoconductive and osteoinductive applications as active bio-mechanical bones for increasing osteoblasts and differentiating stem cells. At the same time, these hybrid nano-composites possess a much improved mechanical strength that exceeds the mechanical deficiencies of the hydrogels traditionally used for bone regeneration and can be applied as an osteoinductive coating for metal trabecular scaffolds. Micro-trabecular metal structures coated with active and osteoinductive biomechanical ceramic-polymeric biomechanical scaffolds are proposed to recreate macro and micro-distribution of bone stresses and deformations.
\end{abstract}

Keywords: Biomimetic, Nano-Composites, Biomaterials

\section{Introduction}

Traditional bone prostheses are mainly made of metals and ceramics with remarkable strength and stiffness, but with high physiological invasiveness.

These implants, which are expected to serve for a much longer period without failure or surgical revision, although they guarantee mechanical and functional wood, occur frequently physiologically and mechanically with the human bone. Failures and lack of long-term reliability result from the incomplete integration with the local physiology of the personal characteristics of the bones and the patient.

To reduce implant invasiveness, a biomimetic approach is suggested; the implant is expected to have an "equivalent stiffness" (combination of material elastic modulus and prosthesis shape) that matches that of a bone area where it is implanted.

The bone modulus varies in size from 4 to $30 \mathrm{GPa}$, depending on the bone type and the direction of measurement (bone orthotropy). Implants of the current implant are isotropic with higher rigidities than bone (for example between 160 and $210 \mathrm{GPa}$ for titanium and steel alloys) that greatly alter the physiological distribution of bone stress.

This modified biomechanical behavior prevents the correct transfer of physiological stress to the adjacent bone, resulting in the reabsorption of the bone around the implant and consequently the implant weakening (this effect is called stress shield).

This unwanted biomechanical invasiveness is due to the fact that the bones are functional and structural complex entities composed of less rigid, open and dense and rigid materials that are combined to provide rigidity both in Orthotropic ortotropic ortotropic forces and in cortical bone forces. Equivalent to the three-dimensional properties of bone tissue should be truly necessary for implanted prostheses to achieve complete complete integration into the host bone tissue (Aversa et al., 2018). 
However, although porous, metallic and ceramic and polymeric biomaterials and other metallic systems (Taylor et al., 2007; Parfitt, 1983; 1994; Martin et al., 1998) have been proposed for the replacement and regeneration of soft and hard tissues, they fulfill both osteoconductive and mechanical.

From a bio-mechanical point of view, the structure must be rigid enough to support physiological tasks, but should not drastically exceed the stiffness of the replaced bone to avoid stress shielding. Attaching the implant to the surface or to the bone matrix should be improved by alternatives to reduce stress protection.

Clinical efficacy and long-term reliability of bone prostheses have been thoroughly investigated by analyzing finite elements to clarify the causes of the new replacement of invasive restoration (Gramanzini et al., 2016; Aversa et al., 2016a; 2016b). Figure 1 summarizes the main methodological steps used in these studies: (a) biophysical bones for investigation, (b) highlighting and weighing macronalysis in fractured bone, (c) stress of microanalyses and strains in the bone implant interface. Peak peak values and regions of bone adaptive properties are shown in Fig. 1d where unused, healthy and overloaded regimens are reported in Fig. 1d (Frost, 1990).

Bone prosthesis interference was recognized at two magnitude levels, namely a micro scale (bone-implant interface, Fig. 1c) and a macro scale (Fig. 1b). The first small scale (Fig. 1c) explains the biological and micromecanic interactions of the synthetic biomaterial with bone-forming cells and highly adaptive adaptive properties, while the second on a macro scale (Fig. 1b) determines the complete biomechanical functionality of the implant material and the ability to restore the distribution of the biologic stress state in the prosthesis. Osteoblasts under specific biochemical and mechanical stimuli mature and turn into osteocytes that mineralize the bone. The activity of osteoclasts under conditions that were not mechanically stimulated after prostheses could induce bone reabsorption in this new state of mechanical equilibrium.

Figure 1d shows the adaptive bone properties that are in the coupling between bone formation and bone reabsorption. This process refers to bone formation in which osteoclast reabsorption via osteoclasts and renewed osteoblast generations of precursors dynamically replace dynamics (Fig. 2). Coupling can then be considered a complex mechanism of dynamic remodeling involving interactions of different types of cells and control stimuli. Mechanical stimulation should include physiological levels of the strain (Fig. 1d) between $50 \mathrm{~m}$ and $3000 \mathrm{~m}$ (Apicella et al., 2011; 2015; Aversa et al., 2009). Over 50 years of osteocyte activity predominates, resulting in bone resorption between 1500 and $3000 \mathrm{~m}$, a slight increase in lamellar bone, predominantly over 3000, with uncontrolled bone growth or resorption.
In the case of bone, which is a structural biological material that undergoes a mechanically induced continuous renewal (Fig. 2), the remodeling process is controlled by a dynamic balance involving osteoclasts (linking bone cells) and homeostatic renewal osteoblasts.

Osteoblasts under specific biochemical and mechanical stimuli may actually mature and turn into osteocytes that mineralize the bone. Instead, the activity of osteoclasts under conditions that were not mechanically stimulated after the prosthesis (i.e., in the stress protection area) could induce bone reabsorption in this new state of bio-mechanical equilibrium (Fig. 2).

Thus, in order to favor biomechanical integration and a longer maintenance period, a customized material, which carries a great combination of high strength and stiffness that fits the bone, must be used. The use of micro-trabecular metal prostheses and scaffolds simulating the behavior of cortical and colon bone has been proposed to recreate the macroscopic distribution of bone stresses and deformities, however, a necessary biomimetic interface is required at the micro-level in which osteon and osteoblasts interact. Nanomaterials Nanomaterials Ceramic-polymer nanomaterials, based on hydrophilic polymers and ceramic nanoparticles, are potential candidates for new customizable biomaterials that will be used to cover porous ortho-orphoric metal structures. The hybrid layer that will come in contact with bone tissue can be customized by the nanofilli content and by choosing the mechanical properties to obtain the biomechanical osteoinductive characteristics necessary to increase the thickening of the bones in the porous structure of the metallic prosthesis. These resulting hybrid systems have the basic mechanical and biological properties that favor local healthy local generations. Specific and adjustable properties that simulate bone tissue that acts on the interface guide microparticle, leading to bone marrow growth and integration into host bone tissue. The main reasons for using the bone skeleton are therefore to provide a bone formation environment, maintain space and provide bone support for the skeleton during the repair process.

New biomaterials that possess hybrid characteristics can be obtained by using nanometers in polymeric matrices (Aversa et al., 2016a; 2017a; 2017c), especially carbon nanofilters such as fullerenes and carbon nanotubes have been proposed to enhance the strength and rigidity of the results nanocomposite materials. Although the use of diamond carbon nanofillers can further improve these properties, some technology challenges in production technology should be overcome.

Graphite is only one of allotropic forms of carbon and is thermodynamically stable at ambient temperatures and pressures, while diamond is another form of allotropic carbon that is stable at high pressures and at a temperature present in a metastable state under ambient conditions (Aversa et al., 2018; Petrescu and Calautit, 2016a; 2016b). 


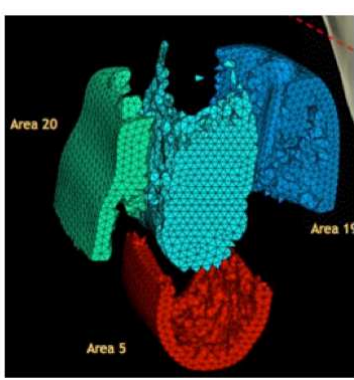

(a)

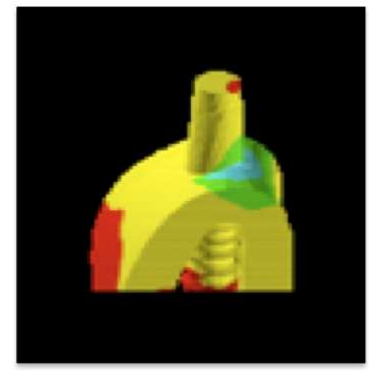

(b)

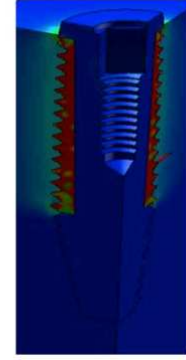

(c)

\section{Peak Bone Strains}
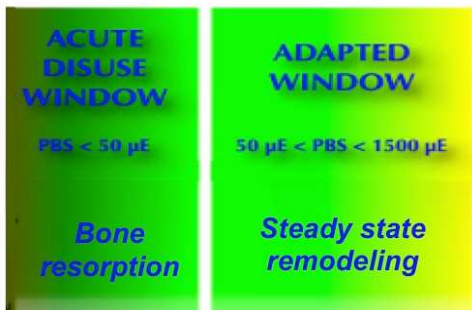

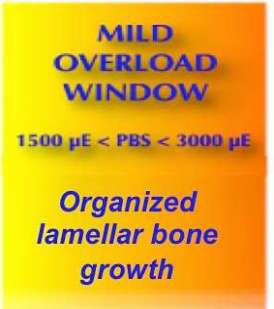

(d)

Fig. 1:Finite element analysis tools for biomechanical and biomimetic investigation: (a) Biofidel models of the bone, (b) Macro Finite element analysis of the implanted bone for definition of the stresses and strains physiological modifications, (c) Micro Finite Element Analysis at the bone-implant interface, (d) Strain limits for bone adaptive properties (Frost, 1998)

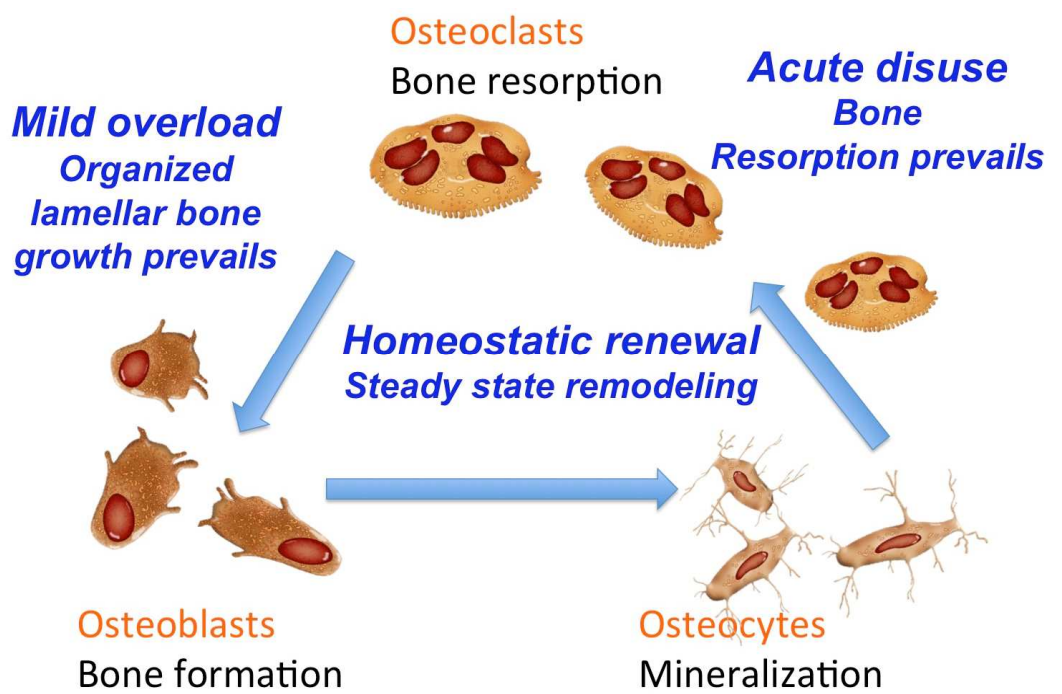

Fig. 2: Bone homeostasis mechanism involving Osteoblast, Osteocyte and Osteoclast cells

Differences in the stability of allotropic forms are a consequence of the large energy barrier separating the $\mathrm{Sp} 2$ graphite (left in Fig. 3) and the configuration of Sp3 diamond (even in Fig. 3), which requires high temperatures and pressures in the presence of catalyst transformation. However, an additional equilibrium parameter involving the surface becomes critical and significant for the distribution of equilibrium energy to nano size: Gibbs free energy is drastically influenced by the presence of surface energy input, modifying the phase diagram of thermodynamic equilibrium (Badziag et al., 1990; Barnard et al., 2003; Barnard and Sternberg, 2007; Viecelli et al., 2001). Atomic models have demonstrated that nanodiamonds with 3 nanometers with tetrahedric hydrocarbons are more stable than the graphite in its polyaromatic form under ambient conditions (Badziag et al., 1990; Aversa et al., 2016a; 2016b; 2016c; 2016d; 2016e). 


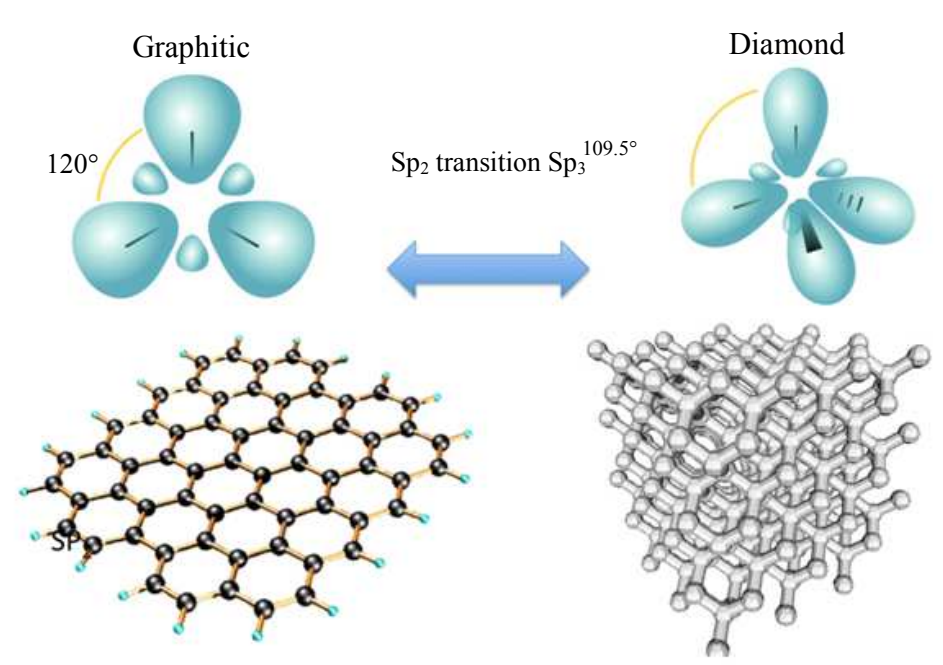

Fig. 3: Left) Graphite (SP2 hybridization) and Right) Diamond (SP3 hybridization) Carbon allotropic forms

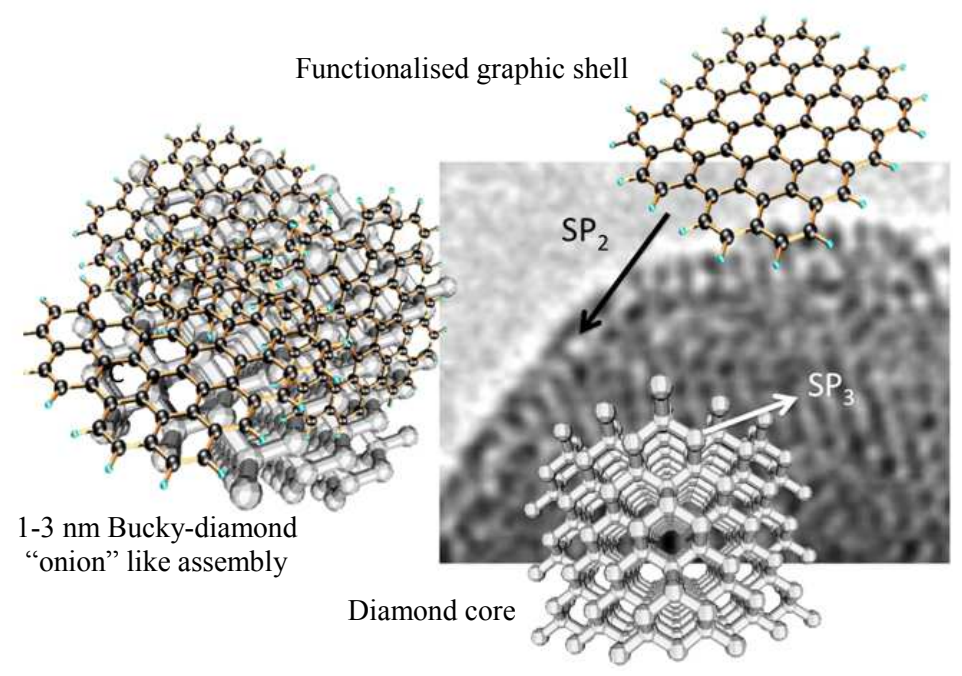

Fig. 4: Bucky-Diamond "onion" like cluster (left side): Nano-diamond core (lower right side) with external graphitic shell (upper right side) and TEM of a detonation nano-diamond atomic structure (right side)

The presence of a more complex structure, generated at the nano-diamond interface, opens up new interesting technology applications. Cuboctodic structures of 1.03 to $3.0 \mathrm{~nm}$ with onion structure characterized by the passage from $\mathrm{Sp} 3$ to $\mathrm{Sp} 2$ carbon at their surfaces were observed by Barnard and Sternberg (2007).

A reversible reverse phase transformation in a nanodiamond-graphite cluster was observed by Xiao et al. (2014) appear in this morphological transition interface that leads to the diamond formation of bucky, characterized by a diamond core, a graphic shell (schematized in Fig. 4) (Barnard and Sternberg, 2007). Such graphite nanodiamond surfaces can be modified using graphite carbon chemistry to form cyclohexene functional systems such as Diels-Alder cycle reactions between conjugated diene and dienophiles (Jarre et al., 2011).
The nano-crystalline Sp2 and Sp3 Carbon structures open up a new perspective for future technological development in structural biomedical applications. The nanocrystalline particles produced by the detonation of explosive carbon materials (Danilenko, 2004; Greiner et al., 1988; Ozawa et al., 2007; Chang et al., 2008) exhibit characteristic dimensions of 3-5 nm. Lubricants, galvanic coatings, polymer nanoparticles, polishing systems and niche applications recently used for electronics, emission devices, catalysts and combustion cells as nanocomposite membranes that lead protons for the application of detonating nanodiamonds have been proposed. However, preliminary clinical and biochemical investigations have shown that these detonation nano-diamonds are biocompatible and nontoxic, opening up new bio-medical applications, 
given both the mild variety of the chemical surface and the mechanical mechanical intrinsic characteristics.

The detonation of nano-diamonds, characterized by different levels of purity and the presence of unwanted functional groups/elements, may not be directly appropriate for biomedical applications in which chemical surface purity and chemical uniformity of the surface (Lai and Barnard, 2011a; 2011b). After raw production, these materials are subjected to purification procedures. A simple method uses surface oxidation and different levels of purity and surface properties can be obtained. Oxidation carried out at elevated temperatures in an air/ozone atmosphere can lead to a purification of the carbon fraction not present as diamond up to $95 \%$ by weight (Osswald et al., 2006; Shenderova et al., 2011).

Oxidation of nano-diamond surfaces other than the removal of unwanted functional compounds forms oxygen-containing groups (the blue dots in Fig. 3 and 4) such as anhydrides and carboxylic acids (Shenderova et al., 2011) which are suitable for hydrogen or polar polarization with the appropriate species.

By air/ozone purification, we can work on the surface of highly reactive and hydrophilic carboxylate, which is very suitable for biomedical applications (Krueger et al., 2008; 2006).

However, the toxicity of nano-diamonds remains controversial and is a real concern. In vitro and in vivo analyzes are needed to evaluate characteristics such as mechanical and physiological behaviors in vivo (Schrand et al., 2009a; 2009b; Zhang et al., 2011; Yuan et al., 2010). Although biocompatibility and negative effect have also been described in the literature on the use of nano silica particles, our published investigations have shown that nano-composite and hybrid materials made by combining amorphous silica nanoparticles have reached a high level of biocompatibility and micro-nanoparticles and p-HEMA. These hydrogel hybrid nanocomposites have been tested for water sorption, water swelling and isotonic saline and for fibroblasts and osteoblasts as cellular response with adhesion, distribution and morphology tests. The presence of polymer-bound silica makes these biomaterials excellent, in terms of pHEMA alone. Good properties of osteoinduction were also observed for differentiation of stem cells from the dental pulp Marrelli et al. (2015). These self-assembled nanostructured composites were also tested as a peri-implanter scheme to accommodate osteoblast growth factors or stem cells to differentiate osteoblasts (Marrelli et al., 2015). This effect was mainly determined by the micromecanic stress stress and the voltage generated at the bone/implant interface.

These new hybrid materials have been shown to be able to stimulate biomechanical bone growth within the range of physiological strains that allow healthy growth to allow for complete early and organized integration of the implant into the receiving bone. Creating ideal scaffolds for bones is a growing argument for research. Such an ideal framework should provide a rigid and elastic mesh to temporarily replace damaged bone function while creating a bioactive substrate for bone regeneration, integrating it fully (Montheard et al., 1992; Kabra et al., 1991; Schiraldi et al., 2004; Aversa et al., 2017a; 2017b).

\section{Materials and Methods}

\section{Materials Preparation}

The $3 \mathrm{~nm}$ detonation nanoparticles (Aldrich, $\geq 97 \%$ ) with a specific surface area of $400 \mathrm{~m}^{2} \mathrm{~g}^{-1}$ were used as bioactive fillers. Nanodiamond hydrophilization was performed (Shenderova et al., 2011; Aversa et al., 2016a-j). The surface graft decomposition followed by functionality consists in the aggregate dispersion of $\sim 20$ $\mathrm{nm}$. Hydrogen treatment at high temperatures led to apical particle nanoparticles, of which a nanodiagnostic fraction of 2-4 $\mathrm{nm}$ was isolated by centrifugation at $>$ 10,000 rpm (Shenderova et al., 2011).

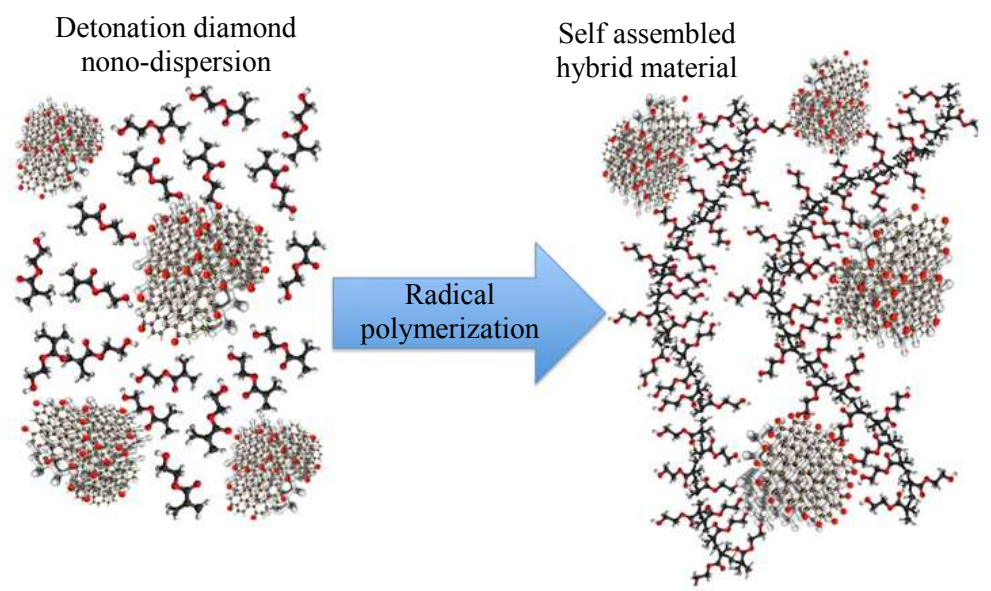

Fig. 5: Self-assembly of HEMA monomers in presence of functionalised Detonation Nano-diamond (left side) and hypothesized Nanodiamonds pHEMA self assembled hybrid nanocomposite (right side) 
The nanodispersion was mixed with 2-hydroxyethyl methacrylate monomers (HEMA) (Sigma-Aldrich Chemicals Co., St. Louis, MO, USA). The suspension of HEMA nanomaterials (Fig. 5) was radically polymerized in the presence of the azoisobutyronitrile thermal initiator (AIBN, Fluka Milano, Italy).

The nanocarbon content was prepared at 2 and $5 \%$ by volume.

The degassed reactive slurry was first transferred to $2.0 \mathrm{~mm}$ thick flat molds and then polymerized at $60^{\circ} \mathrm{C}$ for $24 \mathrm{~h}$. Finally, a cure at $90^{\circ} \mathrm{C}$ was obtained.

\section{Finite Element Analysis (FEA)}

Solid models of odonto dental implants were generated using the Solidwork 2016 software. The titanium implant and the hybrid material replacing one part were cast. The FE model was obtained by importing solid models into ANSYS rel. 9.0 FEM software (Ansys Inc. Houston) using the IGES format. The volumes were linked to tetrahedral elements, resulting in a 3D FE model consisting of 31,240 elements and 35,841 nodes. The precision of the model was verified by the convergence test.

\section{Mechanical Characterization}

The effect of elasticity measurement on the dried, swollen and pendulous p-HEMA nanostructure was performed using a DTM METTLER-TOLEDO mechanical shear modulator (Zurich, Switzerland). The elastic and viscous components of the shear modulus were measured with a constant frequency in an isothermal state. The samples were vacuum dried at $60^{\circ} \mathrm{C}$ for $24 \mathrm{~h}$ before testing. In the shear test mode, discs of $10 \mathrm{~mm}$ diameter and $2 \mathrm{~mm}$ thick discs are placed between three steel plates forming a symmetrical sandwich. An isothermal scan was performed at $37^{\circ} \mathrm{C}$ in a nitrogen purged medium. The deformation control was set at $10 \mu \mathrm{m}$ and a force limit of $0.9 \mathrm{~N}$ was applied at an oscillating frequency of 10 $\mathrm{Hz}$ (Aversa et al., 2018).

\section{Results}

The presence of detonated nano-diamonds functionally oxidized in the monomer reaction mixture favors the self-orientation of HEMA polar monomers (Fig. 5). Nanoparticles are in fact characterized by the presence of oxygen-containing groups leading to a preferential orientation and self-assembly of the HEMA hydroxyl monomer groups at the nanoplaning surface (left side of Fig. 5).

Nanosilica hybrid nanocomposites have been described in a previous paper (Aversa et al., 2016a) to show the self-assembled analog behavior that led to the formation of nanostructured hybrid materials. Similarly, the functional nanodiamond that does not contain the oxygen-binding atoms (red in Fig. 5) and functional HEMA functional groups can produce monomer monomer and monomer. The polymerization of these silicates from HEMA/silica gel leads to the formation of a nanostructured hybrid material exhibiting specific and specific properties such as improved mechanical stiffness and biocompatibility (Aversa et al., 2016a; Petrescu et al., 2016a; 2016b; 2016c.

Applying this model of nanostructure formation to the nanodiamond/HEMA suspension polymerization, a similar improvement in mechanical properties and biocompatibility is expected. However, improved mechanical properties are expected to be more relevant due to the high and high shear force (Azo technology).

The stiffness of the synthetic diamond may be up to 15 times greater than that of silicon, that is, from shear modules of about $450 \mathrm{GPa}$ Vs about $30 \mathrm{GPa}$ (Azo). By acting as filler or hybrid formation, nano-diamond detonation could generate mechanical behavior of hybrids based on similar nanoparticles (Aversa et al., 2016a), the behavior of shear variation according to the volume fraction of diamond nanoparticles in the hybrid material could be evaluated.

As described by Aversa et al. (2016a), plasticization follows the equilibration of pHEMA hybrid nano-silica in physiological solutions. Water molecules that bind to polymeric hydrophilic groups induce a significant plasticization of the nanocomposite (in our case a $16 \%$ by volume nanocomposite) that reduces the shear modulus of the dried initial samples from 8-9 GPa to 0.01-1, 1 GPa 6, Aversa et al., 2016d; 2018).

The compositional dependence of the PHEMA nanonanopulsion shear module is not described by the classical Halpin-Tsai equation (Halpin and Kardos, 1976) valid for particle composites, but a linear dependence is observed. These findings confirmed the hybrid character of pHEMA nano-silica compounds.

On the other hand, the same stiffnesses can be obtained at a much lower volumetric loading by using the nanodiamond, i.e., between 1 and $5 \%$ in the dry state.

Figure 5 shows the hypodized scheme of selfassembled PHEMA nanodiamonds, while Fig. 6 compares the shear modulus that can be obtained using nanoparticulate amorphous particles and nanodiamond crystalline particles. The red points are the 2 and 5\% nano-diamond shear modulus, measured in the shear mode using a dynamic mechanical tester (Aversa et al., 2017c).

These preliminary tests have confirmed our estimated theoretical values for hybrid configurations.

Therefore, the adaptive properties of the bones can benefit from the use of biomechanical and biomechanical materials (biomimetics). 


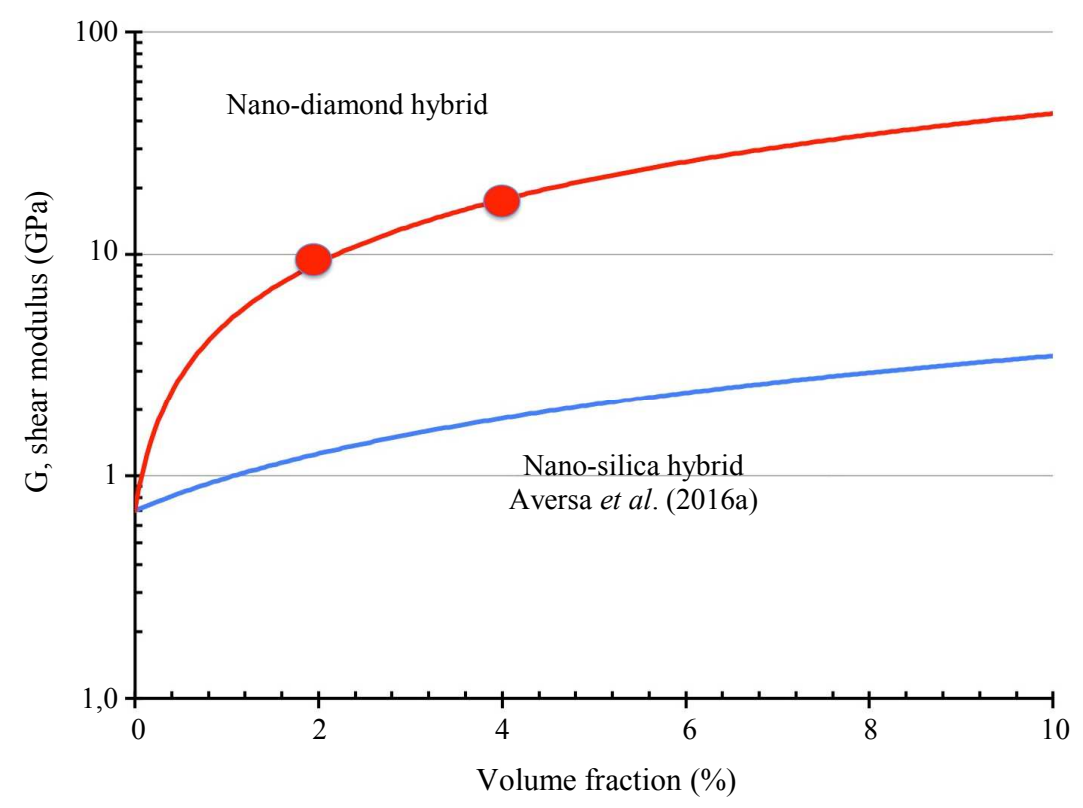

Fig. 6: Camparison of mechanical shear properties on amorphous nanosilica and crystalline nano-diamonds-pHEMA hybrid nano-composite

"In vivo" Evaluation of Bioactivity and
Osteoinduction of Implants

The in vivo study aimed at assessing the bioactivity and osteoinductivity of the ceramic-polymer hybrid scaffold was presented by Aversa et al. (2016g). Unmodified titanium dental implants and siliconized nano-hybrid implants were tested for 2 months at the laboratory hamster femur. Micro-tomography was performed to assess bone density and distribution around the implant.

The biomechanical and active osteoinductive characteristic of hybrid materials is summarized in Fig. 7, where microscopic microscopy and bone reconstruction and biomechanical analysis by finite element analysis are compared for the same active (left) and non-right biomechanical implants.

Active biomechanical coverage (100 microns) demonstrated that it is able to transfer the physiological strains necessary to avoid stress shielding and bone resorption in the vicinity of the implant neck (green cross section in Fig. 7a to 7c).

The uncoated implant (right side of Fig. 7) conversely, shows a significant process of bone resorption in the same area (red circled in Fig. $7 \mathrm{~d}$ to $7 \mathrm{f}$ ) that has been correctly predicted by the use of the biofidel model (Fig. 1b) for the finite element analysis of the implanted bone (Fig. 7f).

The FEM analysis in the same area of the hybrid biomaterial coated implant predicted a more physiological strain distribution due to the biomechanically active interface that stimulates osteoblast growth (Fig. 7c).
Commercial 2-hydroxyethyl methacrylate was purchased from Sigma-Aldrich Chemicals Co., (St. Louis, MO, USA). Fumed silicon dioxide (Aerosil 300 Degussa, Germany) with a mean diameter of $7 \mathrm{~nm}$ and specific surface area of $300 \mathrm{~m}^{2} \mathrm{~g}^{-1}$ was utilized as the bioactive filler. The initiator, $\alpha-\alpha$ ' azoisobutyrronitrile (AIBN), was purchased from Fluka (Milan, Italy). HEMA monomers were mixed with increasing amount of fumed silica (4 to $30 \%$ by volume). The resin was poured in $2 \mathrm{~mm}$ thick plane molds, polymerized in a forced air circulation oven set at $60^{\circ} \mathrm{C}$ for $24 \mathrm{~h}$ and finally post-cured at $90^{\circ} \mathrm{C}$ for $1 \mathrm{~h}$.

The planar samples were used for the aqueous isotonic saline $(0.15 \mathrm{M} \mathrm{NaCl})$ solution sorption and swelling experiments. The aqueous solution uptakes in the initially dry samples were determined at equilibrium by gravimetric measurements in a $0.1 \mathrm{mg}$ Mettler Toledo balance (Milan, Italy). The advancing swelling fronts in the limiting Case II anomalous sorption of the samples were monitored measuring the thickness of the unswollen residual glassy core as a function of time. The equilibrium sorption and swelling experiments were performed at $37^{\circ} \mathrm{C}$ (thermostatic water bath) until constant weight uptake was monitored $(100 \mathrm{~h})$.

The solid models of the odonto-stomatological implants were generated using Solidwork 2007 software. Titanium implant and the hybrid material screw substituting part were modeled. The FE model was obtained by importing the solid models into ANSYS rel. 9.0 FEM software (Ansys Inc. Houston) using IGES format. The volumes were meshed with tetrahedral elements, resulting in a 3D FE model made up of 31,240 309 elements and 35,841 nodes. The accuracy of the model was checked by convergence tests. 


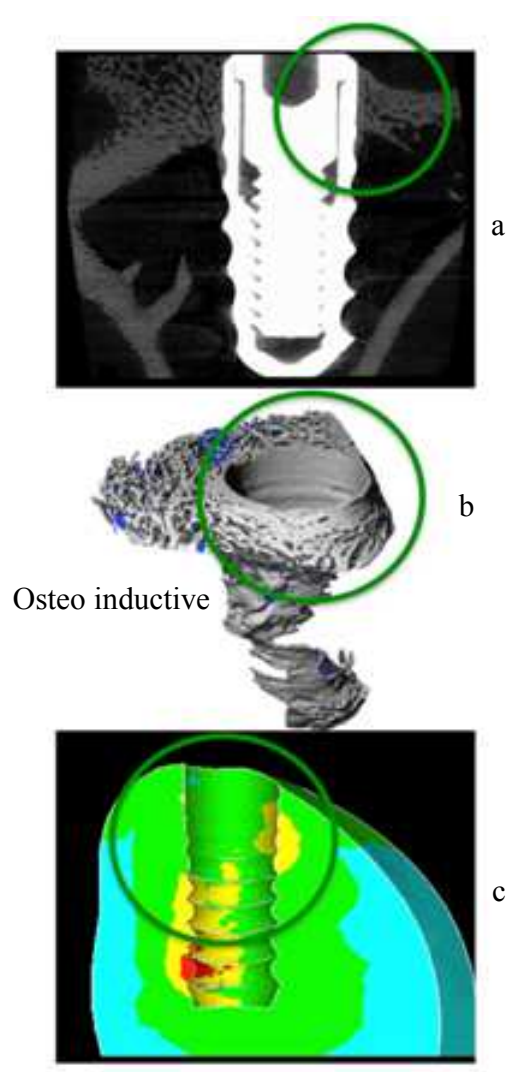

Biomechanically active coating

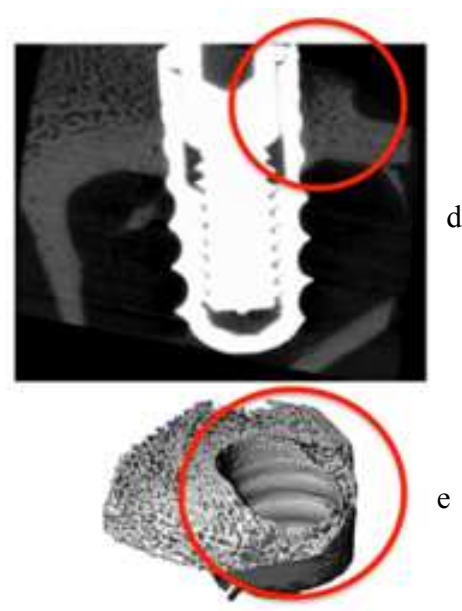

Acute disuse (stress shielding)

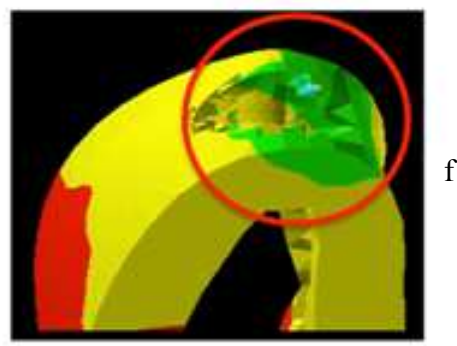

Uncoated

Fig. 7: Comparison of "in vivo" and Finite Element Biomechanical Analysis results on a dental implant with and without the biomechanically and osteoinductive hybrid coating

Shear elastic modulus measurement on dry and swollen p-HEMA Hybrid nano-composite was performed using a METTLER-TOLEDO (Zurich, Switzerland) Dynamical Mechanical tester operating in shear mode (DMA). The elastic and viscous components of the shear modulus were measured under constant frequency in an isothermal condition. The samples were dried under vacuum at a $60^{\circ} \mathrm{C}$ for $24 \mathrm{~h}$ before testing. In the shear test mode, the $10 \mathrm{~mm}$ diameter and $2 \mathrm{~mm}$ thickness sample disks are placed between three steel plates forming a symmetrical sandwich. An isothermal scan at $37^{\circ} \mathrm{C}$ in a dry Nitrogen purged environment was performed. The deformation control was set to $10 \mu \mathrm{m}$ and a force limitation of $0,9 \mathrm{~N}$ was applied at an oscillating frequency of $10 \mathrm{~Hz}$.

The in vitro study was aimed at evaluating the possibility of improving the primary stability of modified oral implants by means of three-dimensional scaffolds in hybrid ceramic-polymeric nanocomposite material (Aversa et al., 2016b; 2016c; 2016d; 2016e; 2016f; 2016g; 2016h; 2016i; Sorrentino et al., 2007; 2009). Both the test and the control fixtures were randomly divided into 4 groups; each test group was made up of 9 implants while each control group consisted of 3 fixtures. At implant placement, insertion torque values ranging between 43.4 and 44.5 and between 44.2 and 45.7 $\mathrm{Ncm}$ were recorded in the test and control group, respectively. In groups 1 to 4 and in groups 5 to 8 , the implants were removed after $1,6,12$ and $24 \mathrm{~h}$. The removal torque values were recorded as previously described. The in vivo study was aimed at evaluating the bioactivity and osteoinductivity of the hybrid ceramicpolymeric scaffold. Unmodified Titanium dental prostheses and modified and coated prostheses were implanted in laboratory rabbit's femur and removed after two months. Micro-Computer Tomography has been run on the explanted femurs and bone density and distribution on the implant has been evaluated.

Our research was aimed to design a biomimetic dental implant finalized to favor adaptive directionally organized OB growth in implanted mandibular bone. In order to achieve this result, both a proper biomimetic scaffolding material and an external implant screw portion have had to be designed.

The biomimetic characteristic of our hybrid materials has been investigated both for mechanical and swelling properties. Physiological bone material behavior to be mimicked by the bioactive scaffolding material relates to the following aspects: 


\section{Mechanical Properties (in the Dry and Swollen States)}

\section{Bioactivity (in vivo Implant)}

The dry Hybrid pHEMA nanocomposite with compositions ranging from 4 to $30 \%$ by volume of nano silica was isothermally shear tested in a Dynamic Mechanical Analyser operating under a Nitrogen dry atmosphere at $10 \mathrm{~Hz}$ and $37^{\circ} \mathrm{C}$. The samples showed a predominantly elastic behavior (the viscous component was negligible for 310 all compositions). The values of the measured Shear moduli are reported in Fig. 8. The measured shear moduli of pHEMA-Nanosilica composites do not follow classical Halpin-Tsai equation for particulate composites (the upward full line reported in Fig. 8). A linear dependence of shear modulus values for the progressively increasing content of nano silica loading has been observed, instead. This unexpected behavior indicates the hybrid nature of the nano-silica pHEMA composites.

In order to define the proper nanofiller/p-HEMA ratio of potentially suitable hybrid nano-composite the target properties requirements are:

Similar to bone rigidity during implantation $(\mathrm{E}=$ 6-15 GPa and $\mathrm{G}=2-4 \mathrm{GPa}$ ) in the dry state

Similar to cartilage and ligament flexibility during osteointegration (when swollen).

Shear moduli comparable to those of the cortical bone have been measured in the dry state for nano silica volumetric fractions ranging from 4 to $12 \%$. A volume fraction of $5 \%$ has been then chosen for sample preparation and FEA simulations (Aversa et al., 2016b-i; Aversa and Apicella, 2016).

Elastic moduli (tensile test) ranging from 2-20 MPa (strain hardening effect) have been measured for the rubbery swollen hybrid composite ( $5 \%$ by volume). This value turns comparable to that of the periodontal ligament strained in the same conditions and to that of an articular cartilage.

The 5\% hybrid nano-composite dramatically swells in isotonic water solution picking up $50 \%$ of its dry weight while reducing its shear modulus down to 2-3 $\mathrm{MPa}$ (measured in the DMA at $10 \mathrm{~Hz}$ ). Such phenomenon is associated with the water induced polymer plasticization that reduces the polymer glass transition temperature below the 311 test temperature. The sorption behavior in a physiological isotonic $0.15 \mathrm{M} \mathrm{NaCl}$ solution held at $37^{\circ} \mathrm{C}$ of our $5 \%$ volume fraction glassy hybrid materials have been investigated for both solution weight uptakes and swelling kinetic. Once exposed to the aqueous solution, the initially dry and glassy pHEMA nanocomposite 2 $\mathrm{mm}$ thick plates starts to swell showing a clear front dividing the rubber-swollen outer portion and the unaffected glassy core. The glassy core thickness progressively reduces the swollen front advance through the sample. A measure of the swelling kinetic, which has been reported in Fig. 9 as a function of the square root of time, is given by the rate of reduction of the glassy core as a function of the time. The observed swelling front initially advanced at a constant rate according to the limiting relaxation controlled anomalous sorption mechanism indicated as "Case II sorption".

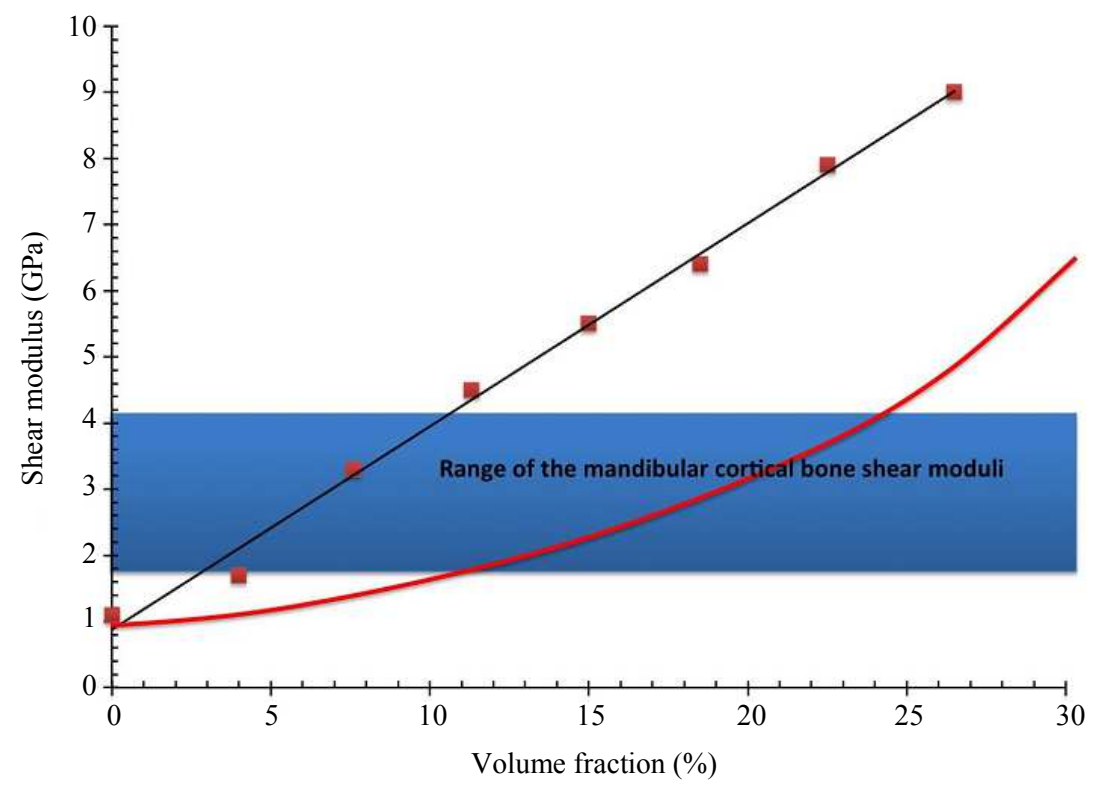

Fig. 8: Shear moduli of the hybrid nanocomposites at different nano silica filler loading. The theoretical Halpin-Tsai curve is reported for comparison in the figure 


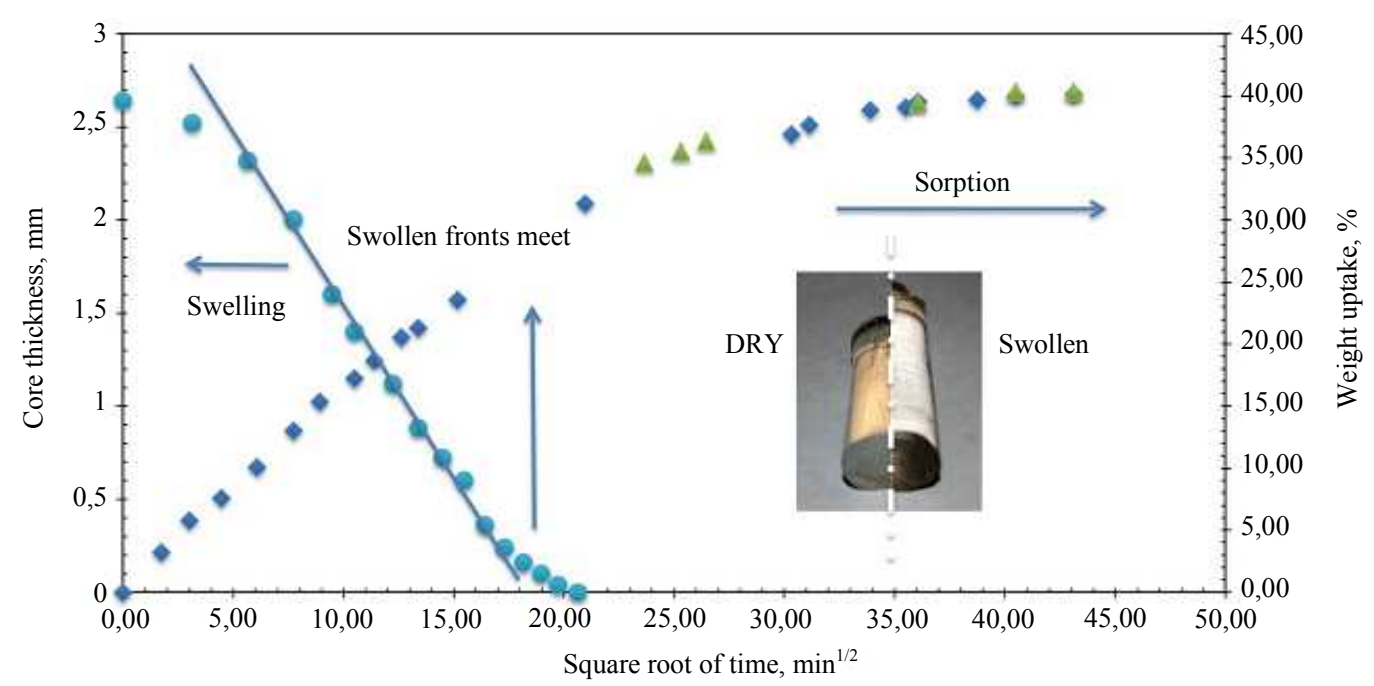

Fig. 9: Swelling and sorption kinetics of a $5 \%$ by volume hybrid nanocomposite in $0.15 \mathrm{M} \mathrm{NaCl}$ water solution (isotonic)

An initial linear swelling rate is of about $0.10 \mathrm{~mm}$ per $\mathrm{h}$. As the swelling goes further, however, a diffusive resistance develops in the outer swollen skin leading to a diffusion controlled swelling of the remaining glassy core. When swelling fronts meet, sample weight uptake is about $27 \%$ but it continues to increase up to the equilibrium value of $40 \%$. This is due to the achievement of a complete equilibrium swelling through the thickness of the sample. At equilibrium, $14.5 \%$ increase in the sample thickness and 50\% volume increases have been measured. These values have been used to evaluate by Finite Element Analysis simulation the dimensional changes occurring in the complex geometry of the modified dental implant described in the subsequent paragraph.

The use of biocompatible and biomechanically active interface has been "designed" to reproduce bonecompatible and biomimetic strain distribution. The ranges of the physiological strains and related bone adaptive properties are reported. There are upper $(>3000 \mu \varepsilon)(<50$ $\mu \varepsilon)$ that do not favor healthy bone growth. Strain ranges of adaptive bone growth are Bone resorption $(<50 \mu \varepsilon)$, Remodelling (50-1500 $\mu \varepsilon)$, Organized growth (1500-3000 $\mu \varepsilon)$, Resorption $(>3000 \mu \varepsilon)$.

Biomimetic aspects are investigated by using the osteoconductive hybrid nano-composite coupled with a FEM modeling of the hybrid material swelling and deformation. The proposed CAD solid model of the new ceramic-polymeric modified implant is shown in Fig. 10.

Two biomechanical functions have been considered while designing the implant: Implant fixation and bone growth stimulus. A portion of the Ti screw has been replaced by the hybrid nano-composite, that maintains the external thread continuity while internally, where the remaining $\mathrm{Ti}$ core is tapered through the screw tip, shows a thickness varying from 0.5 to $0.8 \mathrm{~mm}$. This thickening of the hydrophilic ceramic-polymeric hybrid nanocomposite produces, after swelling, a progressive volumetric increase across the tip. The scaffold should play two biomechanical functions: A structural one, as part of the fixture and a bioactive one, as a bone growth stimulus. Physiologically, the stretching of the periodontal ligament causes new bone apposition in the tooth socket. Since the elastic modulus of the swollen scaffold was comparable to that of the periodontal ligament, the Finite Element Analysis confirmed that the swelling of the nanocomposite could act as a biomechanical bone growth input.

Figure 11 shows the results of a Finite Element Analysis performed on the new implant simulating the ceramic-polymeric insert swelling in a physiological fluid: Displacement up to $0.2 \mathrm{~mm}$ have been calculated (after $8 \mathrm{hrs}$. according to the $0.1 \mathrm{~mm} / \mathrm{hr}$ swelling rate). This occurrence favors prosthetic device fixation and stabilization after implantation (First biomechanical function).

Moreover, considering that remodelling is triggered not by principal stress but strains and that dynamic loads (not static load) on bone trigger remodelling, a positive growth stimulus is given by the presence of a deformable hybrid rubbery interface undergoing physiological (50$3000 \mu \varepsilon$ ) compression and tension straining during bone healing and implant osseointegration (Second biomechanical function), (Aversa et al., 2016 a-i).

Hybrid ceramic-polymeric insert swelling then stabilizes the implant in the bone and creates a biomechanically active interface for bone growth. Stresses on the bone have been modulated by scaffold swelling thickness choice for healthy bone growth. In vivo tests performed using this new modified oral implant confirmed the improved capability of such implants in promoting early osseointegration. 


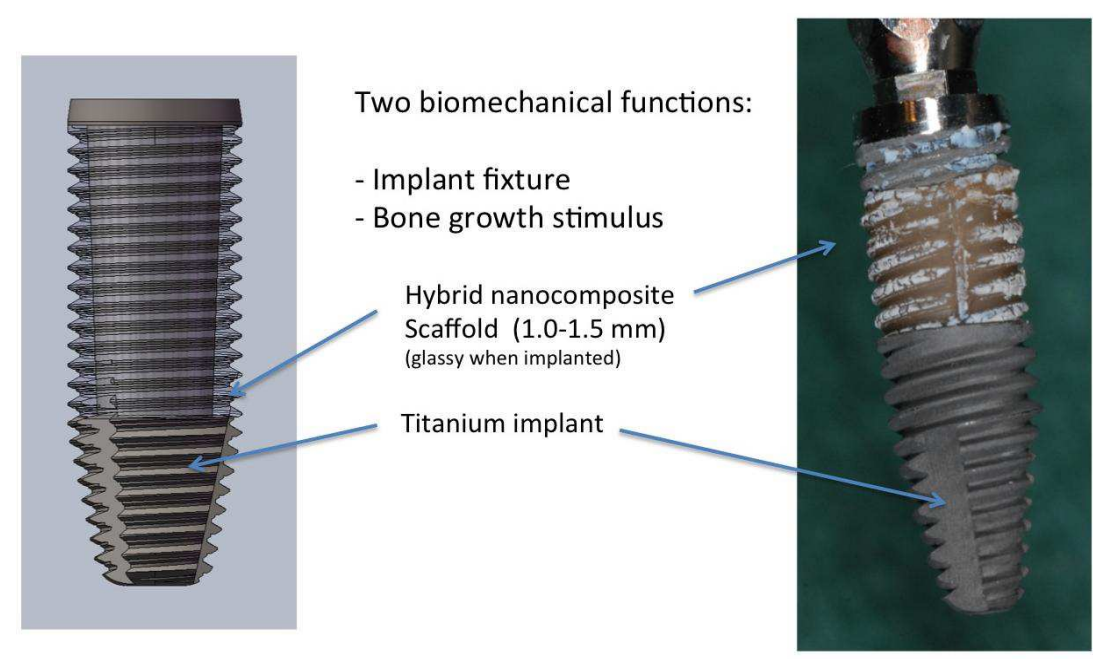

Fig. 10: Thick elastic scaffold hybrid material mimicking periodontal ligament functions in the Biomimetic implant: CAD solid model and a prototype for use in "in vivo" tests of the new ceramic-polymeric modified Titanium implant

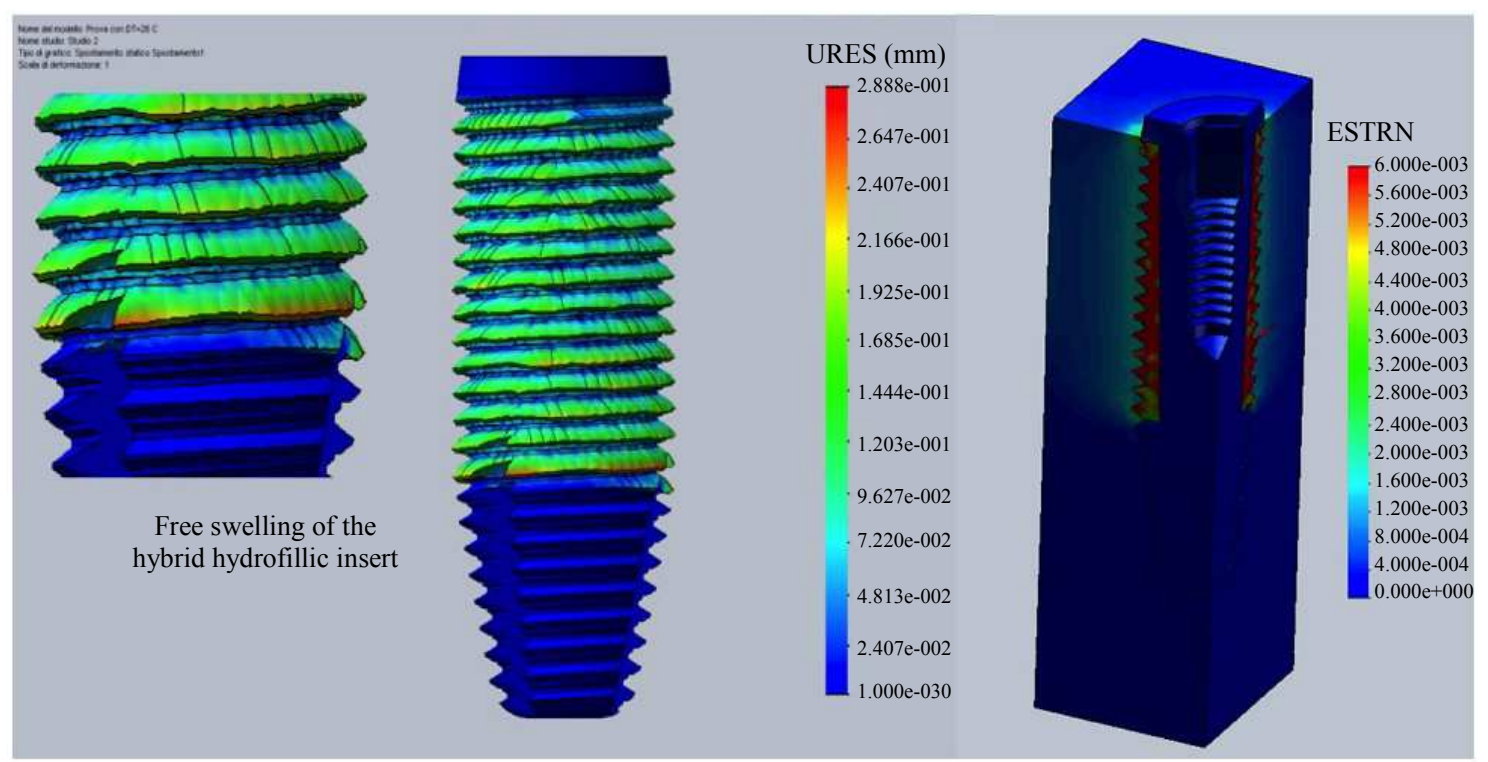

Fig. 11: Displacements (URES) in mm and strains (ESTRN) of the hybrid ceramic-polymeric insert undergoing physiological fluid free and constrained swelling after implantation

The present in vitro study aimed at evaluating the possibility of improving the primary stability of oral implants by means of three-dimensional scaffolds made up of an innovative hybrid ceramic-polymeric nanocomposite material.

In the test groups, the mean removal torque values progressively increased over time (diamond dots), ranging from 61.2 after $1 \mathrm{~h}$ to $86.2 \mathrm{Ncm}$ after $24 \mathrm{~h}$, showing how the swelling of the scaffolds improved implant primary stability. Conversely, in the control groups (square dots), the mean removal torque values ranged between 43.7 and $44.9 \mathrm{Ncm}$.

Figure 12 compares the mean removal torque increases and sorption/swelling kinetics.
The results of the Micro CT investigation are reported in Fig. 13. The thin hybrid scaffold coated implants have shown two main relevant differences in osteoinductivity and bioactivity compared to the unmodified implants:

- avoid bone resorption in the cortical bone surrounding the implant neck

- improved osteoinduction in the medullary bone

Uncoated Titanium implants have shown significant bone resorption at the cortical bone level.

This effect can be related to the improper biomechanical stimulation on the cortical bone outside 
the range of the 50-3000 $\mu \varepsilon$. To avoid this undesired effect due to the proper mechanical stimulation induced by the bioactive hybrid material scaffold interface.
Moreover, the bone growth on the implant surface (left implant in Fig. 13) is due to the osteoinductivity of the tested hybrid scaffolding material (Aversa et al., 2016 b-i).
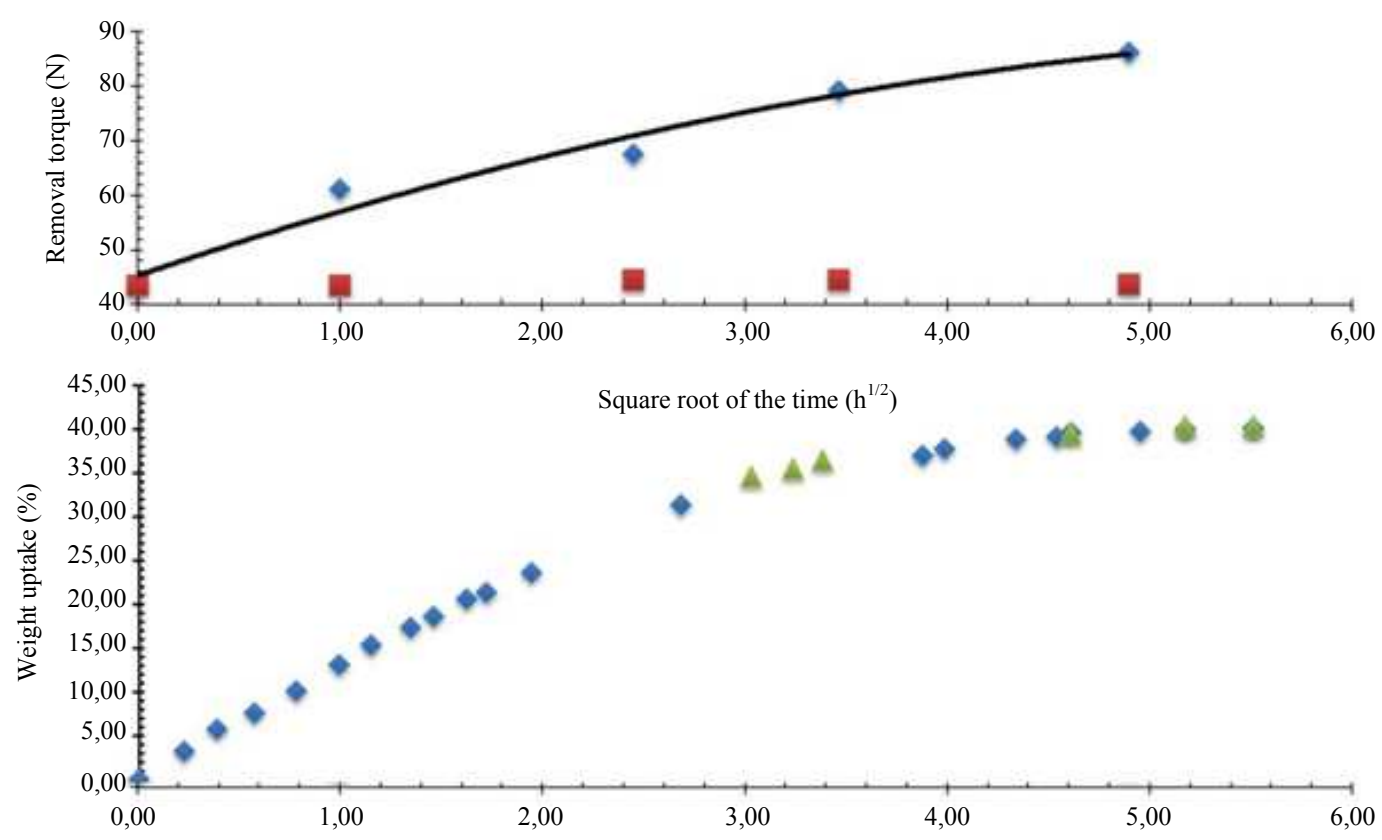

Fig. 12: Comparison between the kinetics of after implantation removal torque increases and physiological fluid uptakes in modified implants undergoing swelling

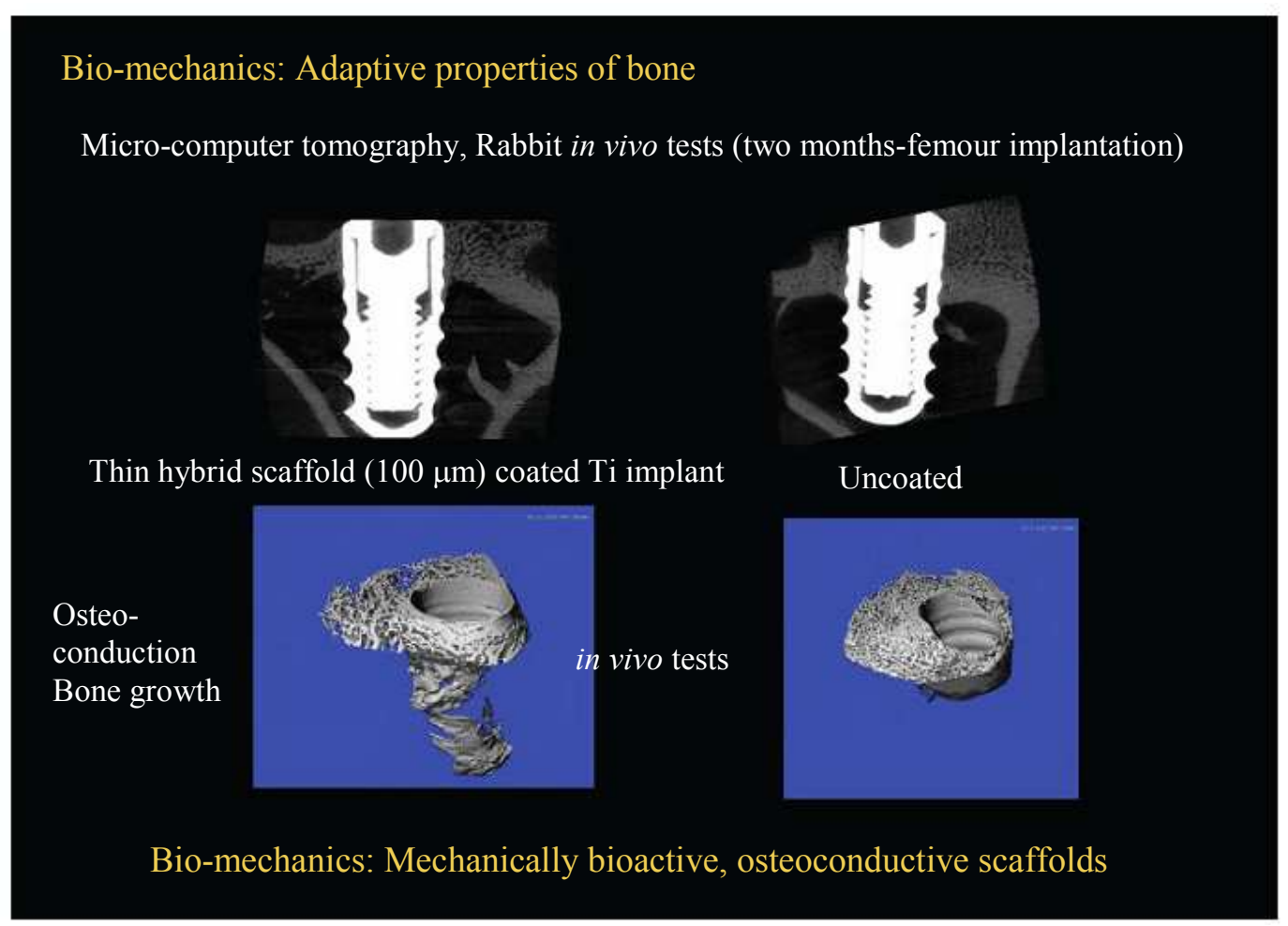

Fig. 13: Biomechanicanics in adaptive morphology of the bone and osteoinduction in the hybrid scaffolding materials 


\section{Discussion}

Biomaterials Today's science is a very interdisciplinary field that plays a central role in the development of tissue engineering applications involving close collaboration between biologists, chemists, material engineers, physicists and clinicians who have researched in this area to a level favorable to the development of new systems. Regenerative medicine has developed a lot and will guarantee many bed-to-bed applications (Montheard et al., 1992; Filmon et al., 2002; Davis et al., 1991; Kabra et al., 1991; Apicella et al., 1993; Peluso et al., 1997; Chow et al., 2010).

Biomimetic Ability (Apicella and Hopfenberg, 1982; Apicella et al., 2010; 2011, 2015; Aversa et al., 2009; Perillo et al., 2010; Petrescu et al., 2015; SchwartzDabney and Dechow, 2003; Töyräsa et al., 2001; Frost, 1990; Gramanzini et al., 2016, Holley et al., 1970; Nicolais et al., 1984; Aversa et al., 2016h; Mirsayar et al., 2017) and regeneration (Aversa et al., 2018).

New hybrid nanoparticles are prepared by polymerizing hydroxy-ethyl-methacrylate monomers filled with detonating nanotubes (up to $5 \%$ by volume). This material absorbs water and swells in aqueous physiological solutions (up to $40-45 \%$ by weight), transforming it into glassy and rubbery conditions. Low levels of non-diamond loads can improve the mechanical properties of hybrid materials.

Hydromechanically compatible hybrid hydrogels can be used as scaffolding materials to increase stress adaptation mechanisms to micro and macro prostheses.

The introduction of active biomechanical interfaces will improve biomimetic implantation while reproducing the biomechanical functions of cartilage and ligaments (Apicella and Hopfenberg, 1982; Apicella et al., 2010; 2011; 2015; Aversa et al., 2009; Perillo et al., 2015; Schwartz-Dabney and Dechow, 2003; Töyräsa et al., 2001; Frost, 1990; Gramanzini et al., 2016; Holley et al., 1970; Nicolais et al., 1984) Positive Effects on Biomechanical Use and CD.

The use of metallic microtrabecular prostheses (Aversa et al., 2016c; 2016d) coated with ceramicpolymeric hybrid scaffolds (Aversa et al., 2016f) was proposed to recreate the macro and micro-distribution of stresses and deformations in the bone.

The development of polymer hybrid nanocomposites has been proposed in recent studies (Aversa et al., 2016e; 2016f; 2018). These hybrid materials can induce the mechanical and biological properties necessary to promote healthy local generations.

The innovative features of a biomimetic approach are that the prosthesis is now designed to replace the joint, damaged by various causes, but does not stimulate tissue regeneration. Also, the average duration of a prosthesis is about 10/15 years, while the new "biomimetic prosthesis" will last longer, estimated at 20/25 years.
This is very important because the average life span has increased significantly, increasing the number of orthopedic surgeries and health and social care costs.

A biomimetic/biomechanical approach has been pursued in designing new bioactive ceramic-polymeric hybrid material modified odonto-stomatological implant for biomechanical stimulation and potential improved scaffold mineralization and ossification.

A new nano-composite hybrid ceramic-polymeric Hydroxyl-Ethyl-Methacrylate polymer (pHEMA) filled with nano silica particles (4-6\% by volume) have been chosen as biomimetic material.

This material swells (about 14\% linearly) in presence of aqueous physiological solution (when in a biological aqueous environment) picking-up to $50-30 \%$ by weight of water (depending on nano silica loading) turning from glassy and rigid to soft and rubbery. Mechanical behavior of the proposed hybrid materials are comparable with those of bone when in the glassy state and to those of the cartilage (ligaments) when rubbery after swelling.

The mechanical bio-mimicking properties of this highly osteoconductive biomaterial have been utilized to develop a new bioactive odonto-stomatological implant. The new concept is driven by the consideration that a bioactive scaffolding interface between the implanted bone and the prosthetic device is generated when the material is able to stimulate the implant surrounding bone in the physiological strain range for healthy bone remodeling and organized growth (50-3000).

The use of mechanically compatible hybrid hydrogels as scaffolding materials are expected to increase prosthesis adaptation mechanisms introducing active interfaces that improve implant biomimetic while reproducing cartilage and ligaments biomechanical functions. Adaptive properties of the bone benefit of the use of biomimetic (biomechanically compatible and bioactive) scaffold biomaterials coupled with new designed odontostomatological prostheses (Aversa et al., 2016a-i).

\section{Conclusion}

The new type of biomimetic implants can find applications in the knee, ankle, hip, shoulder and orthopedic column.

Another area of application of biomimetic schemes is surgical oncology to support and facilitate bone regeneration, resulting in massive losses due to primitive and metastatic tumor elimination interventions.

The prosthetic system could allow for better functional recovery by promoting bone recreation to ensure good maintenance, even if it will have an impact on the quality of life of the individual patient severely compromised by the oncological pathology underlying it. 
The biomimetic solution combining a metal support structure (to guarantee load resistance) an osteoinductive and biomechanically active bone (which promotes bone regeneration) finds replication in all areas of surgical treatment involving bone removal and requires regenerative stimulation of the resected tissue. In fact, the concentrated bone marrow contains growth factors and mesenchymal stem cells that can specialize in bone cells, cartilage cells and tendons.

A biomimetic/biomechanical approach has been pursued in designing new bioactive ceramic-polymeric hybrid material modified odonto-stomatological implant for biomechanical stimulation and potential improved scaffold mineralization and ossification.

A new nano-composite hybrid ceramic-polymeric Hydroxyl-Ethyl-Methacrylate polymer (pHEMA) filled with nano silica particles ( $4-6 \%$ by volume) have been chosen as biomimetic material. This material swells (about 14\% linearly) in presence of aqueous physiological solution (when in a biological aqueous environment) picking-up to $50-30 \%$ by weight of water (depending on nano silica loading) turning from glassy and rigid to soft and rubbery.

Mechanical behavior of the proposed hybrid materials are comparable with those of bone when in the glassy state and to those of the cartilage (ligaments) when rubbery after swelling. The mechanical bio-mimicking properties of this highly osteoconductive biomaterial have been utilized to develop a new bioactive odonto-stomatological implant. The new concept is driven by the consideration that a bioactive scaffolding interface between the implanted bone and the prosthetic device is generated when the material is able to stimulate the implant surrounding bone in the physiological strain range for healthy bone remodeling and organized growth (50-3000).

The use of mechanically compatible hybrid hydrogels as scaffolding materials are expected to increase prosthesis adaptation mechanisms introducing active interfaces that improve implant biomimetic while reproducing cartilage and ligaments biomechanical functions. Adaptive properties of the bone benefit of the use of biomimetic (biomechanically compatible and bioactive) scaffold biomaterials coupled with new designed odontostomatological prostheses.

\section{Acknowledgement}

The Authors acknowledge Liquid Metals Technologies Inc, Ca USA that kindly supplies the samples for the characterization.

\section{Funding Information}

This research has been funded by Italian Ministry of University and Research project FIRB Future in Research 2008, project RBFR08T83J.

\section{Author's Contributions}

All the authors contributed equally to prepare, develop and carry out this manuscript.

\section{Ethics}

This article is original and contains unpublished material. Authors declare that are not ethical issues and no conflict of interest that may arise after the publication of this manuscript.

\section{References}

Apicella, A., B. Cappello, M.A. Del Nobile, M.I. La Rotonda and G. Mensitieri et al., 1993. Poly(ethylene oxide) (PEO) and different molecular weight PEO's blends monolithic devices for drug release. Biomaterials, 142: 83-90.

DOI: 10.1016/0142-9612(93)90215-N

Apicella, A. and H. Hopfenberg, 1982. Water-swelling behavior of an ethylene-vinyl alcohol copolymer in the presence of sorbed sodium chloride. J. Applied Polymer Sci., 27: 1139-1148. DOI: 10.1002/app.1982.070270404

Apicella, D., R. Aversa, E. Ferro, D. Ianniello and A. Apicella, 2010. The importance of cortical bone orthotropicity, maximum stiffness direction and thickness on the reliability of mandible numerical models. J. Biomed. Mater. Res., 93: 150-163.

DOI: 10.1002/jbm.b.31569

Apicella, D., M. Veltri, P. Balleri, A. Apicella and M. Ferrari, 2011. Influence of abutment material on the fracture strength and failure modes of abutmentfixture assemblies when loaded in a bio-faithful simulation. Clin. Oral Implants Res., 22: 182-188: DOI: $10.1111 /$ j.1600-0501.2010.01979.x

Apicella, D., R. Aversa, M. Tatullo, M. Simeone and S. Sayed et al., 2015. Direct restoration modalities of fractured central maxillary incisors: A multi-levels validated finite elements analysis with in vivo strain measurements. Dental Mater., 31: e289-e305. DOI: 10.1016/j.dental.2015.09.016

Aversa, R., D. Apicella, L. Perillo, R. Sorrentino and F. Zarone et al., 2009. Non-linear elastic threedimensional finite element analysis on the effect of endocrown material rigidity on alveolar bone remodeling process. Dental Mater., 25: 678-690: DOI: $10.1016 /$ j.dental.2008.10.015

Aversa, R., R. Sorrentino and A. Apicella, 2016a. Biomechanically active ceramic-polymeric hybrid scaffolds for tissue engineering. Proceedings of the International Conference on Biological Sciences and Technology, (BST' 16), Atlantis Press, pp: 308-318. 
Aversa, R., F.I.T. Petrescu, R.V. Petrescu and A. Apicella, 2016b. Biomimetic FEA bone modeling for customized hybrid biological prostheses development. Am. J. Applied Sci., 13: 1060-1067. DOI: 10.3844/ajassp.2016.1060.1067

Aversa, R., F.I.T. Petrescu, R.V. Petrescu and A. Apicella, 2016c. Biofidel FEA modeling of customized hybrid biological hip joint prostheses, Part I: Biomechanical behavior of implanted femur. Am. J. Biochem. Biotechnol., 12: 270-276.

DOI: $10.3844 /$ ajbbsp.2016.270.276

Aversa, R., F.I.T. Petrescu, R.V.V. Petrescu and A. Apicella, 2016d. Biomimetic finite element analysis bone modeling for customized hybrid biological prostheses development. Am. J. Applied Sci., 13: 1060-1067. DOI: 10.3844/ajassp.2016.1060.1067

Aversa, R., D. Parcesepe, R.V. Petrescu, G. Chen and F.I.T. Petrescu et al., 2016e. Glassy amorphous metal injection molded induced morphological defects. Am. J. Applied Sci., 13: 1476-1482.

DOI: 10.3844/ajassp.2016.1476.1482

Aversa, R., R.V. Petrescu, F.I.T. Petrescu and A. Apicella, 2016f. Smart-factory: Optimization and process control of composite centrifuged pipes. Am. J. Applied Sci., 13: 1330-1341.

DOI: 10.3844/ajassp.2016.1330.1341

Aversa, R., F. Tamburrino, R.V. Petrescu, F.I.T. Petrescu and M. Artur et al., 2016g. Biomechanically inspired shape memory effect machines driven by muscle like acting NiTi alloys. Am. J. Applied Sci., 13: 1264-1271.

DOI: 10.3844/ajassp.2016.1264.1271

Aversa, R., F.I.T. Petrescu, R.V.V. Petrescu and A. Apicella, 2016h. Flexible stem trabecular prostheses. Am. J. Eng. Applied Sci., 9: 1213-1221. DOI 10.3844/ajeassp.2016.1213.1221

Aversa, R., R.V.V. Petrescu, A. Antonio and F.I.T. Petrescu, 2016i. Physiologic human fluids and swelling behavior of hydrophilic biocompatible hybrid ceramo-polymeric materials. Am. J. Eng. Applied Sci., 9: 962-972.

DOI: 10.3844/ajeassp.2016.962.972.

Aversa, R. and A. Apicella, 2016. Near critical carbon dioxide sorption induced crystallization in PET. Am. J. Eng. Applied Sci., 9: 846-853.

DOI: 10.3844 ajeassp.2016.846.853

Aversa, R., R.V.V. Petrescu, A. Apicella and F.I.T. Petrescu, 2017a. Nano-diamond hybrid materials for structural biomedical application. Am. J. Biochem. Biotechnol., 13: 34-41.

DOI: 10.3844/ajbbsp.2017.34.41

Aversa, R., D. Parcesepe, R.V. Petrescu, F. Berto and G. Chen et al., 2017b. Processability of bulk metallic glasses. Am. J. Applied Sci., 14: 294-301.

DOI: 10.3844/ajassp.2017.294.301
Aversa, R., R.V. Petrescu, A. Apicella and F.I.T. Petrescu, 2017c. Modern transportation and photovoltaic energy for urban ecotourism. Transylvanian Rev. Admin. Sci., 13: 5-20.

DOI: 10.24193/tras.SI2017.1

Avers, R., R. Petrescu, F.I.T. Petrescu and A. Apicella, 2018. Nanodiamond for structural biomimetic scaffolds. MSCE 6: 6-17. DOI: $10.4236 /$ msce. 2018.64002

Badziag, P., W.S. Verwoerd, W.P. Ellis and N.R. Greiner, 1990, Nanometre-sized diamonds are more stable than graphite. Nature, 343: 244-245. DOI: $10.1038 / 343244 \mathrm{a} 0$

Barnard, A.S., S.P. Russo and I.K. Snook, 2003. Structural relaxation and relative stability of nanodiamond morphologies. Diamond Relat. Mater., 12: $1867-1872$. DOI: $10.1016 / \mathrm{S} 0925-9635(03) 00275-9$

Barnard, A.S. and M. Sternberg, 2007. Crystallinity and surface electrostatics of diamond nanocrystals. J. Mater. Chem., 17: 4811-4819.

DOI: $10.1039 / b 710189 a$

Chang, Y.R., J.H. Hsu, K. Chen and W. Fann, 2008. Mass production and dynamic imaging of fluorescent nanodiamonds. Nature Nanotech., 3: 284-288. DOI: $10.1038 /$ nnano.2008.99

Chow, E.K., X.Q. Zhang, M. Chen, R. Lam and E. Robinson et al., 2010. Nanodiamond therapeutic delivery agents mediate enhanced chemoresistant tumor treatment. Sci. Transl. Med., 3: 73ra21-73ra21. DOI: $10.1126 /$ scitranslmed.3001713

Danilenko, V.V., 2004. On the history of the discovery of nanodiamond synthesis. Phys. Solid State, 46: 595-599. DOI: 10.1134/1.1711431

Davis, P.A., S.J. Huang, L. Nicolais and L. Ambrosio, 1991. Modified PHEMA Hydrogels. In: High Performance Biomaterials, Szycher, M. (Ed.), Technonic, Lancaster, PA, USA, pp: 343-68.

Filmon, R., F. Grizon, M.F. Baslie and D. Chappard, 2002. Effects of negatively charged groups (carboxymethyl) on the calcification of poly(2hydroxyethylmethacrylate). Biomaterials, 23: 3053-3059. DOI: 10.1016/S0142-9612(02)00069-8

Frost, H.M., 1990. Structural Adaptations to Mechanical Usage (SATMU). 2. Redifining Wolff's law: The bone remodelling problem. Anat. Rec., 226: 414-422. DOI: 10.1002/ar.1092260403

Gramanzini, M., S. Gargiulo, F. Zarone, R. Megna and A. Apicella et al., 2016. Combined microcomputed tomography, biomechanical and histomorphometric analysis of the peri-implant bone: A pilot study in minipig model. Dental Mater., 32: 794-806: DOI: 10.1016/j.dental.2016.03.025

Greiner, N.R., D.S. Phillips, J.D. Johnson and F. Volk, 1988. Diamonds in detonation soot. Nature, 333: 440-442. DOI: $10.1038 / 333440 \mathrm{a} 0$ 
Halpin, J.C. and J.L. Kardos, 1976. The Halpin-Tsai equations: A review. Polymer Eng. Sci., 16: 344-352. DOI: $10.1002 /$ pen.760160512

Holley, R.H., H.B. Hopfenberg and V. Stannett, 1970. Anomalous transport of hydrocarbons in polystyrene. Polymer Eng. Sci., 10: 376-382. DOI: $10.1002 /$ pen.760100612

Jarre, G., Y.J. Liang, P. Betz, D. Lang and A. Krueger, 2011. Playing the surface game-Diels-Alder reactions on diamond nanoparticles. Chem. Commun., 47: 544-546. DOI: 10.1039/C0CC02931A

Kabra, B., S.H. Gehrke, S.T. Hwang and W. Ritschel, 1991. Modification of the dynamic swelling behaviour of pHEMA. J. Applied Polym. Sci., 42: 2409-2416. DOI: 10.1002/app.1991.070420906

Krueger, A., J. Stegk, Y.J. Liang, L. Lu and G.B. Jarre, 2008. Nanodiamond: Simple and efficient functionalization of detonation diamond. $\mathrm{E}$ Langmuir, 24: 4200-4204. DOI: 10.1021/la703482v

Krueger, A., Y.J. Liang, G. Jarre and J. Stegk, 2006, Surface functionalisation of detonation diamond suitable for biological applications. J. Mater. Chem., 16: 2322-2328. DOI: 10.1039/B601325B

Lai, L. and A.S. Barnard, 2011a. Modeling the thermostability of surface functionalisation by oxygen, hydroxyl and water on nanodiamonds. Nanoscale, 3: 2566-2575. DOI: 10.1039/c1nr10108k

Lai, L. and A.S. Barnard, 2011b. Stability of nanodiamond surfaces exposed to N, NH and NH2. J. Phys. Chem. C, 115: 6218-6228. DOI: 10.1021/jp1111026

Marrelli, M., G. Falisi, A. Apicella, D. Apicella and M. Amantea et al., 2015. Behaviour of dental pulp stem cells on different types of innovative mesoporous and nanoporous silicon scaffolds with different functionalizations of the surfaces. J. Biol. Regulators Homeostatic Agents, 9: 991-997. PMID: 26753666

Martin, R.B., D.B. Burr and N.A. Sharkey, 1998. Skeletal Tissue Mechanics. 1st Edn., Springer, New York, ISBN-10: 0387984747, pp: 392.

Mirsayar, M.M., V.A. Joneidi, R.V. Petrescu, F.I.T. Petrescu and F. Berto, 2017. Extended MTSN criterion for fracture analysis of soda lime glass. Eng. Fracture Mechan., 178: 50-59. DOI:_10.1016/j.engfracmech.2017.04.018

Mohan, N., C.S. Chen, H.H. Hsieh, Y.C. Wu and H.C. Chang, 2010. In vivo imaging and toxicity assessments of fluorescent nanodiamonds in Caenorhabditis elegans. Nano Lett., 10: 3692-3699. DOI: $10.1021 / \mathrm{nl} 1021909$

Montheard, J.P., M. Chatzopoulos and D. Chappard 1992. 2-hydroxyethylmethacrylate HEMA; chemical properties and applications in biomedical fields. J. Macromol. Sci. Macromol. Rev., 32: 1-34.

DOI: $10.1080 / 15321799208018377$
Nicolais, L., A. Apicella and C. de Notaristefano, 1984. Time-temperature superposition of $n$-hexane sorption in polystyrene. J. Membrane Sci., 18: 187-196. DOI: $10.1016 / \mathrm{S} 0376-7388(00) 85033-4$

Ozawa, M., M. Inaguma, M. Takahashi, F. Kataoka and A. Krüger et al., 2007. Preparation and behavior of brownish, clear nanodiamond colloids. Adv. Mater., 19: 1201-1206. DOI: 10.1002/adma.200601452

Osswald, S., G. Yushin, V. Mochalin, S.O. Kucheyev and Y. Gogotsi, 2006. Control of sp2/sp3 carbon ratio and surface chemistry of nanodiamond powders by selective oxidation in air. J. Am. Chem. Soc., 128: 11635-11642. DOI: 10.1021/ja063303n

Parfitt, A.M., 1983. The Physiological and Clinical Significance of Bone Histomorphometric Data. In: Bone Histomorphometry: Techniques and Interpretation, Recker, R.R. (Ed.), CRC Press, Boca Raton, pp: 143-223.

Parfitt, A.M., 1994. Osteonal and hemi-osteonal remodeling: The spatial and temporal framework for signal traffic in adult human bone. J. Cell Biochem., 55: 273-286. DOI: 10.1002/jcb.240550303

Peluso, G, O. Petillo, J.M. Anderson, M. Ambrosio and L. Nicolais et al., 1997. The differential effects of poly(2-hydroxyethylmethacrylate) and poly(2hydroxyethylmethacrylate)/poly(caprolactone) polymers on cell proliferation and collagen synthesis by human lung fibroblasts. J. Biomed. Mater. Res., 34: 327-336. DOI: $10.1002 /($ SICI)10974636(19970305)34:3<327::AID-JBM7>3.0.CO;2-M

Perillo, L., R. Sorrentino, D. Apicella, A. Quaranta and E.D. Gherlone et al., 2010. Nonlinear visco-elastic finite element analysis of porcelain veneers: A submodelling approach to strain and stress distributions in adhesive and resin cement. J. Adhesive Dentistry, 12: 403-413.

Petrescu, F.I.T., E. Buzea, L. Nănuţ, M. Neacşa and C. Nan, 2015. The role of antioxidants in slowing aging of skin in a human, analele univers. Craiova Biol. Horticultura Tehn. Prel. Prod. Agr. Ing. Med., 20: 567-574.

Petrescu, R.V., R. Aversa, A. Apicella, S. Li and G. Chen et al., 2016a. Something about electron dimension. Am. J. Applied Sci., 13: 1272-1276. DOI: 10.3844/ajassp.2016.1272.1276

Petrescu, R.V., R. Aversa, A. Apicella, F. Berto and S. Li et al., 2016b. Ecosphere protection through green energy. Am. J. Applied Sci., 13: 1027-1032.

DOI: 10.3844/ajassp.2016.1027.1032

Petrescu, F.I.T., A. Apicella, R.V. Petrescu, S.P. Kozaitis and R.B. Bucinell et al., 2016c. Environmental protection through nuclear energy. Am. J. Applied Sci., 13: 941-946. DOI: 10.3844/ajassp.2016.941.946

Petrescu, F.I.T. and J.K. Calautit, 2016a. About nano fusion and dynamic fusion. Am. J. Applied Sci., 13: 261-266. DOI: 10.3844/ajassp.2016.261.266 
Petrescu, F.I.T. and J.K. Calautit, 2016b. About the light dimensions. Am. J. Applied Sci., 13: 321-325. DOI: 10.3844/ajassp.2016.321.325

Shenderova, O., A. Koscheev, N. Zaripov, I. Petrov and Y. Skryabin et al., 2011. Surface chemistry and properties of ozone-purified detonation nanodiamonds. J. Phys. Chem. C, 115: 9827-9837. DOI: $10.1021 /$ jp1102466

Schrand, A.M., J. Johnson, L. Dai and E. Ōsawa, 2009a. Cytotoxicity and Genotoxicity of Carbon Nanomaterials. In: Safety of Nanoparticles: From Manufacturing to Medical Applications, Nanostructure Science and Technology. Webster, T.J. (Ed.), ISSN-10: 1571-5744, pp: 159-187.

Schrand, A.M., S.A.C. Hens and O.A. Shenderova, 2009b. Nanodiamond particles: Properties and perspectives for bioapplications. Crit. Rev. Solid State Mater. Sci., 34: 18-74.

DOI: $10.1080 / 10408430902831987$

Sorrentino, R., D. Apicella, C. Riccio, E.D. Gherlone and F. Zarone et al., 2009. Nonlinear visco-elastic finite element analysis of different porcelain veneers configuration. J. Biomed. Mater. Res., 91: 727-736. DOI: $10.1002 / \mathrm{jbm} . b .31449$

Sorrentino, R., R. Aversa, V. Ferro, T. Auriemma and F. Zarone et al., 2007. Three-dimensional finite element analysis of strain and stress distributions in endodontically treated maxillary central incisors restored with different post, core and crown materials. Dent Mater., 23: 983-993.

DOI: $10.1016 /$ j.dental.2006.08.006

Schiraldi, C., A. D'Agostino, A. Oliva, F. Flamma and A. De Rosa et al., 2004. Development of hybridmaterials based on hydroxyethylmethacrylate as supports for improving cell adhesion and proliferation. Biomaterials, 25: 3645-3653.

DOI: 10.1016/j.biomaterials.2003.10.059
Schwartz-Dabney, C.L. and P.C. Dechow, 2003. Variation in cortical material properties throughout the human dentate mandible. Am. J. Phys. Anthropol., 120: 252-277. DOI: 10.1002/ajpa.10121

Taylor, D., J.G. Hazenberg and T.C. Lee, 2007. Living with cracks: Damage and repair in human bone. Nat. Mater., 6: 263-268. DOI: 10.1038/nmat1866

Töyräsa, J., T. Lyyra-Laitinena, M. Niinimäkib, R. Lindgrenc and M.T. Nieminenb et al., 2001. Estimation of the Young's modulus of articular cartilage using an arthroscopic indentation instrument and ultrasonic measurement of tissue thickness. J. Biomechan., 34: 251-256. DOI: 10.1016/S0021-9290(00)00189-5

Viecelli, J.A., S. Bastea, J.N. Glosli and F.H. Ree, 2001. Phase transformations of nanometer size carbon particles in shocked hydrocarbons and explosives. J. Chem. Phys., 115: 2730-2736.

DOI: $10.1063 / 1.1386418$

Xiao, J., G. Ouyang, P. Liu, C.X. Wang and G.W. Yang, 2014. Reversible Nanodiamond-Carbon Onion Phase Transformations, Nano Letters, ACS publications, 3645-3652: DOI: 10.1021/nl5014234

Yuan, Y., X. Wang, G. Jia, J.H. Liu and T. Wang et al., 2010. Pulmonary toxicity and translocation of nanodiamonds in mice. Diamond Relat. Mater., 19: 291-299. DOI: 10.1016/j.diamond.2009.11.022

Zhang, Q., V.N. Mochalin, I. Neitzel, I.Y. Knoke and J. Han et al. 2011. Fluorescent PLLA-nanodiamond composites for bone tissue engineering. Biomaterials, 32: 87-94.

DOI: 10.1016/j.biomaterials.2010.08.090 